\title{
Plasticidade morfoanatômica foliar de Tibouchina clavata (Melastomataceae) ocorrente em duas formações de restinga
}

\author{
Foliar morphoanatomic plasticity of Tibouchina clavata \\ (Melastomataceae) in two restinga formations
}

\author{
Maick Willian Amorim ${ }^{1}$ \& João Carlos Ferreira de Melo Júnior ${ }^{1,2}$
}

\begin{abstract}
Resumo
Respostas plásticas em plantas podem ser induzidas pela heterogeneidade espacial, sendo a restinga um ecossistema favorável à compreensão dessas respostas em função das condições ambientais limitantes que apresenta. O presente estudo avaliou de forma comparada as respostas plásticas foliares em duas populações de Tibouchina clavata (Melastomataceae) habitando as formações herbácea e florestal da restinga do Parque Estadual Acaraí, localizada em São Francisco do Sul-SC. Nos dez indivíduos amostrais de cada formação foram mensurados atributos morfoanatômicos foliares e do caule. Variáveis ambientais como nutrição edáfica, umidade gravimétrica e radiação luminosa foram mensuradas. As médias obtidas para cada variável foram comparadas pelo teste t de Student. Para cada atributo, foi calculado o índice de plasticidade fenotípica. Atributos morfológicos e anatômicos diferenciaram as duas populações entre si, sendo a população da formação herbácea tipicamente xeromórfica em função das condições ambientais mais restritivas. Condições mais favoráveis dadas pela maior oferta de nutrientes e água no ambiente florestal proporcionaram maior investimento dos indivíduos em crescimento. Atributos anatômicos mostraram-se pouco plásticos quando comparados aos morfológicos. T. clavata demonstrou ser uma espécie morfologicamente plástica que permite a compreensão dos efeitos dos fatores limitantes da restinga sobre o desenvolvimento vegetal, com destaque às condições nutricional, hídrica e lumínica que induzem ao xeromorfismo.
\end{abstract}

Palavras-chave: índice de plasticidade, floresta de restinga, morfoanatomia funcional, planície costeira, restinga herbácea.

\begin{abstract}
Plastic responses in plants can be induced by spatial heterogeneity, being the restinga a supportive ecosystem to understand these responses due to its limiting environmental conditions. This study evaluated so compared the leaf plastic responses in two populations of Tibouchina clavata (Melastomataceae) inhabiting the herbaceous and forest formations of the restinga Acaraí State Park, located in São Francisco do Sul-SC. In the ten individuals sample of each formation were measured leaf morphoanatomic attributes and stem. Environmental variables such as edaphic nutrition, gravimetric moisture and light radiation were measured. Mean values for each variable were compared by the Student $t$ test. For each attribute, it was calculated phenotypic plasticity index. Morphological and anatomical attributes differentiate the two populations together, and the population of herbaceous formation typically xeromorphic due to more stringent environmental conditions. More favorable terms given by the increased supply of nutrients and water in the forest environment provided greater investment of growing individuals. Anatomical attributes were shown little plastic when compared to the morphological. T. clavata it proved to be a morphologically plastic kind that allows the understanding of the effects of the limiting factors of the restinga on plant development, with emphasis on nutrition, water and luminous conditions that induce xeromorphism.

Key words: plasticity index, forest restinga, functional morpho-anatomy, coastal plain, herbaceous restinga.
\end{abstract}

\footnotetext{
${ }^{1}$ Universidade da Região de Joinville, Depto. Ciências Biológicas, Lab. Anatomia e Ecologia Vegetal, R. Paulo Maschitzki 10, 89219-710, Joinville, SC, Brasil.

${ }^{2}$ Autor para correspondência: jcmelo_wood@hotmail.com
} 


\section{Introdução}

Melastomataceae é uma família que possui aproximadamente 150 gêneros e 4500 espécies, com distribuição predominantemente pantropical (Almeda et al. 2015). No Brasil, são encontrados cerca de 67 gêneros e 1373 espécies (Goldenberg et al. 2012; BFG 2015). A família está bem distribuída nas diversas formações vegetacionais de Santa Catarina e grande parte das espécies ocorre em Floresta Atlântica stricto sensu e formações associadas (Wurdack 1962; Goldenberg 2004). No estado de Santa Catarina ocorrem 130 espécies em 13 gêneros (BFG 2015), com destaque para Tibouchina Wurdack (1962).

O gênero Tibouchina Aubl. é composto por 167 espécies nativas, das quais 146 são endêmicas do Brasil (BFG 2015). Apesar da grande representatividade na flora neotropical, Tibouchina não é um gênero muito estudado no âmbito da morfoanatomia funcional. Tibouchina clavata (Pers.) Wurdack, conhecida popularmente como orelha-de-onça, apresenta forma de vida arbustiva, variando de 0,3 a 3 metros de altura, com folhas verde-escuras e densa pilosidade serícea de coloração branco-acinzentada (Guimarães \& Martins 1997). Endêmica do Brasil, ocorre nos estados do Rio de Janeiro, São Paulo, Paraná e Santa Catarina (Meyer 2008), podendo ser encontrada em áreas abertas com vegetação em regeneração, na Floresta Ombrófila Densa de Terras Baixas e nas formações pioneiras de influência marinha, como as restingas (Melo Júnior \& Boeger 2015).

A vegetação de restinga tem grande distribuição ao longo da costa brasileira e apresenta diferenças fisionômicas reconhecíveis, desde vegetação herbácea até formações florestais que são definidas, em geral, pelo distanciamento da influência marinha (Melo Júnior \& Boeger 2015). Diversos estudos têm avaliado as alterações morfoanatômicas em espécies de restinga, sendo a maioria realizada em apenas uma subformação (Boeger \& Wisniewski 2003; Chagas et al. 2008; Baraloto et al. 2010). Entretanto, trabalhos que correlacionam características morfoanatômicas às diferentes fisionomias da restinga ao longo de gradientes ambientais são escassos (Bachtold \& Melo Júnior 2015; Melo Júnior \& Boeger 2016). Tais estudos têm mostrado que espécies cujas populações se distribuem em formações contíguas de restinga, embora exibam diferenças estruturais, possuem padrões de resposta plástica consideravelmente baixos. Isto sugere o forte efeito da microescala espacial sobre a herdabilidade de certos atributos biológicos apesar das contrastantes condições nutricionais e de disponibilidade hídrica dos solos das formações de restinga (Bachtold \& Melo Júnior 2015; Melo Júnior \& Boeger 2016; Silva et al. 2016).

Com o objetivo de ampliar o conhecimento sobre os padrões de resposta funcional em plantas das formações de restinga do Parque Estadual Acaraí, estado de Santa Catarina, no contexto do Programa de Pesquisa em Biodiversidade da Mata Atlântica, o presente estudo verificou a ocorrência de alterações morfológicas e anatômicas foliares em populações de Tibouchina clavata (Melastomataceae) habitando as formações herbácea e florestal de restinga. Temse como hipótese que as condições de nutrição edáfica, disponibilidade de água e luminosidade, encontradas na formação de restinga próxima ao mar são precursoras de respostas estruturais xeromórficas quando comparadas às observadas no ambiente florestal.

\section{Material e Métodos}

Área de estudo

O estudo foi realizado no município de São Francisco do Sul, estado de Santa Catarina (261'소 $\left.48^{\circ} 31^{\prime} \mathrm{W}\right)$, no Parque Estadual Acaraí, em parcelas do módulo RAPELD de duas formações distintas: a restinga herbácea $(\mathrm{RH})$ e a floresta de restinga (FR) (Fig. 1). A RH ocupa as primeiras faixas de areia da região pós-praia, tem como característica a presença de dunas fixas e móveis formadas por depósitos eólicos (Cordazzo et al. 2006) e de solo classificado como Neossolo Quartzarênico, sendo nutricionalmente pobre e com déficit hídrico (Melo Júnior \& Boeger 2015). FR está distante cerca de dois quilômetros do mar, e é caracterizada pela presença de solo Espodossolo Ferrihumilúvico e Organossolo Háplico de natureza hidromórfica, apresentando nível mais elevado de umidade, solos com maior teor de matéria orgânica e de nutrientes minerais assimiláveis, e vegetação de porte arbóreo (Melo Júnior \& Boeger 2015). O clima da área é mesotérmico, influenciado pela umidade marítima (Cfa) segundo a Köppen (1948), a temperatura média anual é de $21,2^{\circ} \mathrm{C}$ e a precipitação média é de $1830 \mathrm{~mm} / \mathrm{ano}$ (CLIMATE-DATA 2015). 

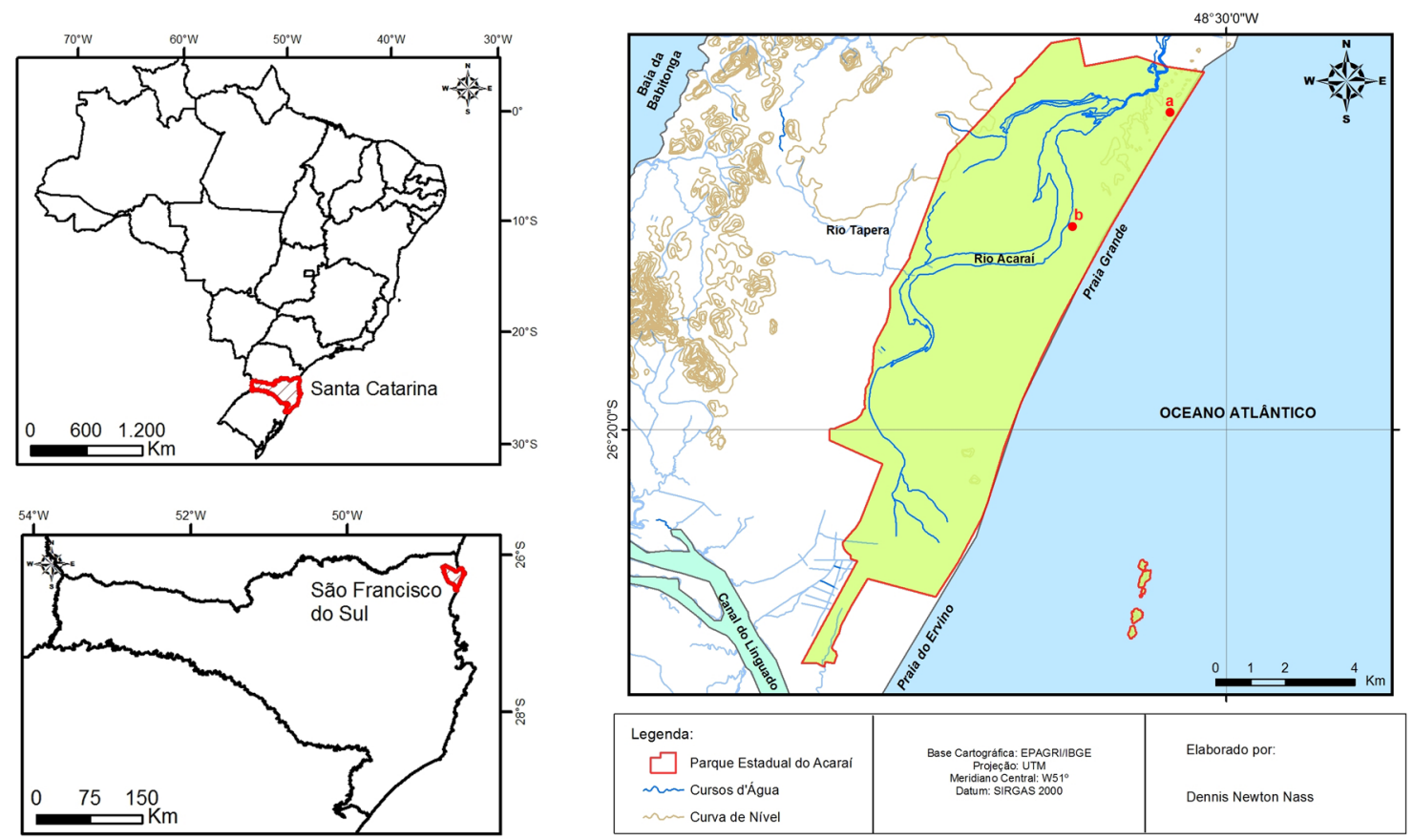

Figura 1 - À esquerda, localização espacial da área de estudo no Brasil e em Santa Catarina. À direita, localização do Parque Estadual Acaraí, São Francisco do Sul e respectivos pontos de coleta de Tibouchina clavata (Melastomataceae) - a. Restinga herbácea; b. Floresta de Restinga.

Figure 1 - To de left, spatial location of study area in Brazil and Santa Catarina. To the right, location of Acaraí State Park, São Francisco do Sul, and respective collection points of Tibouchina clavata (Melastomataceae) - a. herbaceous Restinga; b. Restinga forest.

\section{Variáveis ambientais}

Solos das duas formações foram coletados por meio da abertura de 10 covas de $15 \mathrm{~cm}$ de profundidade em cada formação de restinga estudada. Após homogeneização, obtiveram-se duas amostras compostas, conforme método proposto por Embrapa (2013). A análise química dos solos foi realizada pelo Laboratório de Análise do Solo, da Empresa de Pesquisa Agropecuária e Extensão Rural de Santa Catarina (EPAGRI). A umidade gravimétrica dos solos foi obtida por meio da diferença de massa de solo recém coletado e seco em estufa por $72 \mathrm{~h}$ a $105^{\circ} \mathrm{C}$ (EMBRAPA 2013), a partir de 10 amostras por formação, coletadas na proximidade imediata aos indivíduos amostrados, uma amostra por indivíduo.

A radiação fotossinteticamente ativa (PAR) foi mensurada sobre a copa dos indivíduos por meio de equipamento luxímetro (Li-250A LICOR, USA), com 10 medidas por indivíduo amostrado.

\section{Coleta e análise de material vegetal}

Em cada formação (RH e FR) foram selecionados dez indivíduos de Tibouchina clavata, totalizando um grupo amostral de 20 indivíduos, nos quais foram mesuradas a altura e o diâmetro basal do caule. De cada indivíduo 20 folhas completamente expandidas, do terceiro e quarto nós, a partir do ápice do ramo, sob influência direta do sol, foram coletadas. Destas 20 folhas, 10 foram saturadas em água por $12 \mathrm{~h}$ e usadas para mensuração da massa fresca (gramas) em balança analítica. Em seguida, as folhas foram prensadas e secas em estufa de circulação de ar a $70^{\circ} \mathrm{C}$ por $72 \mathrm{~h}$ para determinação da massa seca (gramas) em balança analítica. O grau de suculência $\left(\mathrm{g} . \mathrm{cm}^{-2}\right)$ foi obtido a partir da relação entre o conteúdo de água (massa fresca - massa seca) e a área foliar. A área foliar $\left(\mathrm{cm}^{2}\right)$ foi obtida por meio de imagem digitalizada em scanner de mesa acoplado ao software Sigma Scan Pro (versão 5.0, SPSS Inc., Chicago IL, USA). A área específica foliar $\left(\mathrm{AEF}, \mathrm{cm}^{2} \times \mathrm{g}^{-1}\right)$ foi calculada pela razão entre a área foliar e a massa seca (Witkowski \& Lamont 1991). As 10 folhas restantes foram fixadas em campo em solução de formalina, etanol e ácido acético (Johansen 1940) para as análises anatômicas. Para a confecção dos cortes histológicos, o terço médio da lâmina foliar foi incluído em historresina 
Leica (GMA-glicol metacrilato). Os blocos foram seccionados transversalmente em micrótomo rotatório Leica RM2125, com cerca de $8 \mu \mathrm{m}$ de espessura e corados com fucsina básica. Lâminas permanentes foram confeccionadas utilizando resina sintética do tipo verniz vitral como meio de montagem (Paiva et al. 2006). A biometria dos tecidos foliares foi obtida por meio da captura de imagem em software Dino-Eye (Anmo Eletronics Corporation) acoplado ao fotomicroscópio Olympus CX 200 Japão. Foram considerados como atributos anatômicos a espessura, em micrômetros, da epiderme nas faces adaxial e abaxial, incluindo a cutícula, do parênquima paliçádico e do parênquima lacunoso.

\section{Tratamento estatístico}

As médias e os respectivos desvios-padrão, baseados em $n=200$, foram calculados para todos os atributos morfoanatômicos foliares observados. Seguido o teste de normalidade, os valores médios dos atributos foram comparados por teste $t$ de Student com nível de significância de 5\% (Zar 1999), em software R (Borcard et al. 2011). Para cada variável morfoanatômica observada foi calculado o índice de plasticidade fenotípica (IPF), sendo IPF = média máxima média mínima / média máxima (Valladares et al. 2006).

\section{Resultados}

A análise química dos solos, apresentada na Tabela 1, evidenciou que ambas as formações analisadas apresentam solo pouco ácido. No solo florestal (FR), os teores dos macronutrientes fósforo $(\mathrm{P})$ e cálcio $(\mathrm{Ca})$ foram encontrados em maiores níveis. Para o solo na formação herbácea $(\mathrm{RH})$, o potássio $(\mathrm{K})$ obteve os maiores valores. Não houve diferença entre as formações com relação ao magnésio $(\mathrm{Mg})$. A concentração de sódio $(\mathrm{Na})$, a soma de bases $(\mathrm{SB})$, a capacidade de troca catiônica (CTC), a acidez real que determina a efetiva CTC do solo $(\mathrm{H}+\mathrm{Al})$, assim como o teor de matéria orgânica (MO), foram maiores na formação florestal. A saturação por bases (V) apresentou maior valor para o solo da formação herbácea. Mesmo com diferença nutricional expressiva, ambos os solos são considerados distróficos (Tab. 1). A umidade gravimétrica média observada nas amostras coletadas na formação herbácea foi 10 vezes menor que na formação florestal.

A radiação fotossinteticamente ativa incidente sobre os indivíduos amostrais diferiu entre as duas formações de restinga analisadas, sendo cerca de $25 \%$ superior na formação herbácea em relação à florestal (Tab. 1).

Todos os atributos morfoanatômicos foliares analisados tiveram variações significativas entre

Tabela 1 - Valores médios das variáveis nutricionais dos solos $(n=10)$, umidade gravimétrica $(n=10)$ e radiação fotossinteticamente ativa $(n=100)$ em restinga herbácea $(\mathrm{RH})$ e floresta de restinga $(\mathrm{FT})$.

Table 1 - Average values of nutritional parameters of soils $(n=10)$, gravimetric moisture $(n=10)$ and photosynthetically-active radiation $(\mathrm{n}=100)$ in herbaceous restinga $(\mathrm{HR})$ and restinga forest (FT) .

\begin{tabular}{|c|c|c|}
\hline \multirow[b]{2}{*}{ Variáveis edáficas } & \multicolumn{2}{|c|}{ Formação } \\
\hline & Restinga Herbácea & Floresta de Restinga \\
\hline $\mathrm{PH}$ & 5,80 & 5,40 \\
\hline $\mathrm{P}\left(\mathrm{mg} / \mathrm{dm}^{3}\right)$ & 7,00 & 6,40 \\
\hline $\mathrm{K}\left(\mathrm{mmolc} / \mathrm{dm}^{3}\right)$ & 10,00 & 14,00 \\
\hline $\mathrm{Ca}\left(\mathrm{mmolc} / \mathrm{dm}^{3}\right)$ & 0,70 & 1,00 \\
\hline $\operatorname{Mg}\left(\mathrm{mmolc} / \mathrm{dm}^{3}\right)$ & 0,10 & 0,10 \\
\hline $\mathrm{Na}\left(\mathrm{mg} / \mathrm{dm}^{3}\right)$ & 10,00 & 12,00 \\
\hline $\mathrm{H}+\mathrm{Al}\left(\mathrm{mmolc} / \mathrm{dm}^{3}\right)$ & 0,90 & 1,50 \\
\hline $\mathrm{SB}\left(\mathrm{mmolc} / \mathrm{dm}^{3}\right)$ & 0,83 & 1,17 \\
\hline CTC $\left(\mathrm{mmolc} / \mathrm{dm}^{3}\right)$ & 1,73 & 2,67 \\
\hline V $(\%)$ & 47,93 & 43,93 \\
\hline $\mathrm{MO}\left(\mathrm{g} / \mathrm{dm}^{3}\right)$ & 0,10 & 0,90 \\
\hline Umidade gravimétrica $(\mathrm{g})$ & 0,09 & 0,95 \\
\hline Radiação fotossinteticamente ativa $\left(\mu \mathrm{mol} \mathrm{m} \mathrm{m}^{-2} \mathrm{~s}^{-1}\right)$ & $1.263,10$ & 975,20 \\
\hline
\end{tabular}


Tabela 2 - Atributos funcionais de Tibouchina clavata (Melastomataceae) nas formações herbácea e florestal da restinga do Parque Estadual Acaraí, São Francisco do Sul-SC. Os valores representam as médias \pm desvios-padrão. Letras diferentes na mesma linha indicam diferença estatística ao nível de $\mathrm{p}<0,05$.

Table 2 - Functional traits of Tibouchina clavata (Melastomataceae) in herbaceous and forest formations of the restinga Acaraí State Park, São Francisco do Sul-SC. Values are means \pm standard deviations. Different letters on the same line indicate statistical difference at $\mathrm{p}<0.05$.

\begin{tabular}{lcc}
\hline \multirow{2}{*}{ Atributos } & \multicolumn{2}{c}{ Fisionomia } \\
\cline { 2 - 3 } & Herbácea & Florestal \\
\hline Altura $(\mathrm{cm})$ & $0,30^{\mathrm{b}} \pm 0,08$ & $0,91^{\mathrm{a}} \pm 0,20$ \\
Diâmetro basal do caule $(\mathrm{cm})$ & $0,35^{\mathrm{b}} \pm 1,39$ & $6,89^{\mathrm{a}} \pm 1,39$ \\
Massa fresca foliar $(\mathrm{g})$ & $0,34^{\mathrm{b}} \pm 0,05$ & $0,95^{\mathrm{a}} \pm 0,27$ \\
Massa seca foliar $(\mathrm{g})$ & $0,09^{\mathrm{b}} \pm 0,03$ & $0,32^{\mathrm{a}} \pm 0,08$ \\
Área foliar $\left(\mathrm{cm}^{2}\right)$ & $6,32^{\mathrm{b}} \pm 0,99$ & $21,69^{\mathrm{a}} \pm 5,16$ \\
Área específica foliar $\left(\mathrm{cm}^{2} / \mathrm{g}^{-1}\right)$ & $68,20^{\mathrm{b}} \pm 27,22$ & $77,42^{\mathrm{a}} \pm 11,60$ \\
Grau de suculência $\left(\mathrm{g} \cdot \mathrm{cm}^{-2}\right)$ & $0,32^{\mathrm{b}} \pm 0,05$ & $0,93^{\mathrm{a}} \pm 0,27$ \\
Conteúdo de matéria seca $\left(\mathrm{g} \cdot \mathrm{g}^{-1}\right)$ & $4,06^{\mathrm{a}} \pm 1,46$ & $2,93^{\mathrm{b}} \pm 0,27$ \\
Epiderme adaxial + cutícula $(\mu \mathrm{m})$ & $23,19^{\mathrm{a}} \pm 2,56$ & $18,63^{\mathrm{b}} \pm 2,66$ \\
Epiderme abaxial + cutícula $(\mu \mathrm{m})$ & $9,83^{\mathrm{a}} \pm 1,42$ & $9,22^{\mathrm{b}} \pm 1,21$ \\
Parênquima paliçádico $(\mu \mathrm{m})$ & $76,47^{\mathrm{a}} \pm 10,73$ & $62,36^{\mathrm{b}} \pm 12,26$ \\
Parênquima lacunoso $(\mu \mathrm{m})$ & $54,45^{\mathrm{b}} \pm 4,13$ & $56,28^{\mathrm{a}} \pm 11,58$ \\
\hline
\end{tabular}

as duas populações de Tibouchina clavata (Tab. 2). Os atributos morfológicos que apresentaram maior variação entre as populações foram a altura e a área foliar. Os valores relativos à altura, ao diâmetro basal do caule, às massas foliares fresca e seca, à área, à área específica foliar e ao grau de suculência foram superiores na formação florestal, enquanto apenas o conteúdo de matéria seca foi maior na formação herbácea. Os maiores valores de espessura da epiderme na face adaxial,

Tabela 3 - Índice de Plasticidade Fenotípica dos atributos funcionais morfo-anatômicos de Tibouchina clavata (Melastomataceae) das formações herbácea e florestal da restinga do Parque Estadual Acaraí, São Francisco do Sul-SC. Table 3 - Phenotypic Plasticity Index of morphological and anatomical functional traits of Tibouchina clavata ( Melastomataceae ) of herbaceous and forest formations of the restinga Acaraí State Park, São Francisco do Sul-SC .

\begin{tabular}{ll}
\hline Atributo & IPF \\
\hline Altura $(\mathrm{cm})$ & 0.67 \\
Diâmetro basal do caule $(\mathrm{cm})$ & 0.94 \\
Massa fresca foliar $(\mathrm{g})$ & 0.64 \\
Massa seca foliar $(\mathrm{g})$ & 0.71 \\
Área foliar $\left(\mathrm{cm}^{2}\right)$ & 0.70 \\
Área específica foliar $\left(\mathrm{cm}^{2} / \mathrm{g}^{-1}\right)$ & 0.11 \\
Grau de suculência $\left(\mathrm{g} \cdot \mathrm{cm}^{-2}\right)$ & 0.65 \\
Conteúdo de matéria seca $\left(\mathrm{g} \cdot \mathrm{g}^{-1}\right)$ & 0.27 \\
Epiderme adaxial + cutícula $(\mu \mathrm{m})$ & 0.19 \\
Epiderme abaxial + cutícula $(\mu \mathrm{m})$ & 0.06 \\
Parênquima paliçádico $(\mu \mathrm{m})$ & 0.18 \\
Parênquima lacunoso $(\mu \mathrm{m})$ & 0.03 \\
\hline
\end{tabular}



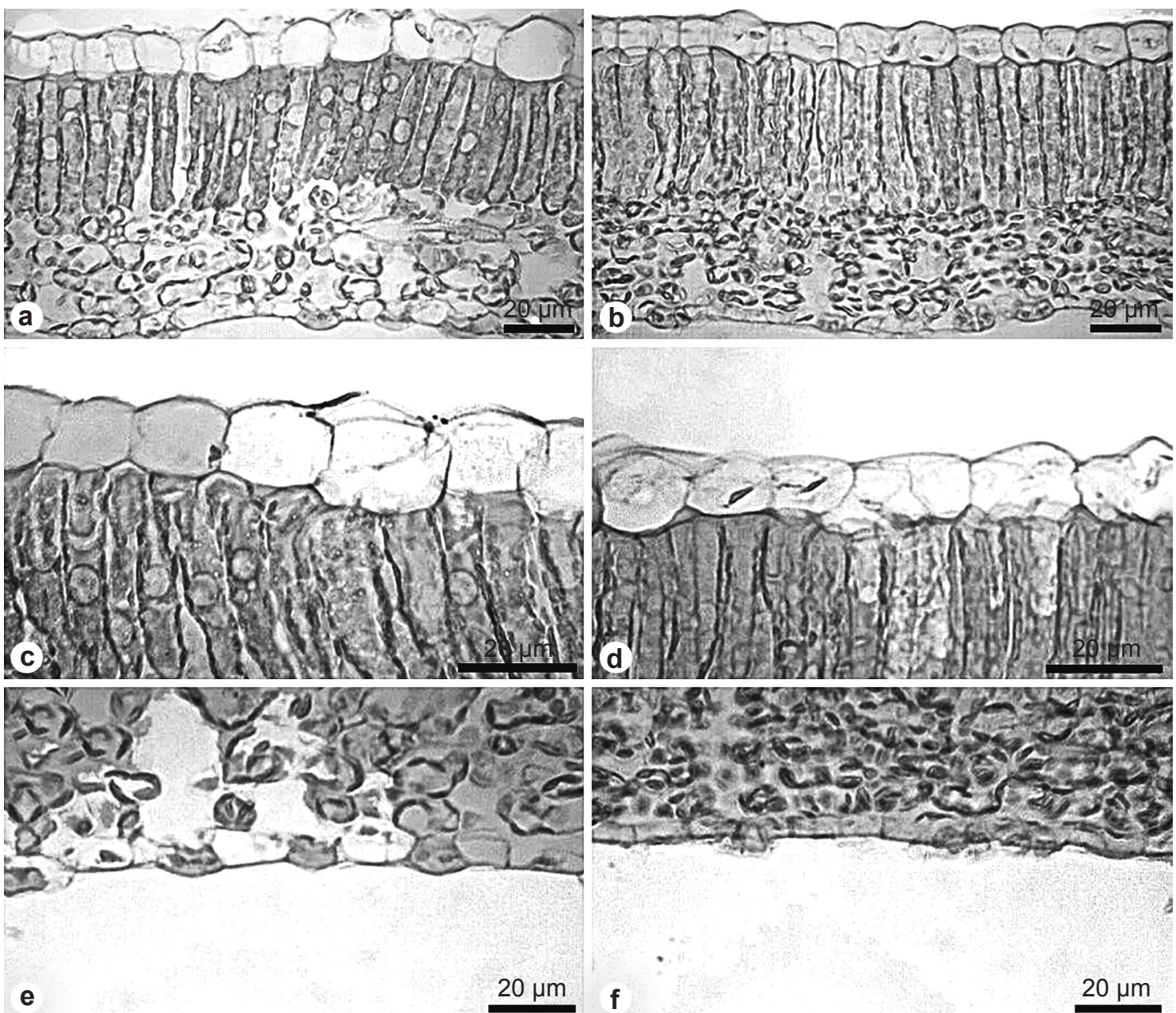

Figura 2 - Anatomia foliar comparada de Tibouchina clavata (Melastomataceae) - a,c,e. Restinga herbácea; b,d,f. Floresta de Restinga; a,b. espessura dos parênquimas paliçádico e lacunoso; c,d. espessura da epiderme na face adaxial e cutícula; e,f. espessura epiderme na face abaxial e cutícula. Barra de escala $=20 \mu \mathrm{m}$.

Figure 2 - Comparative leaf anatomy of Tibouchina clavata (Melastomataceae) - a,c,e. herbaceous Restinga; b,d,f. Restinga Forest; a,b. palisade and spongy parenchyma thickness; c,d. adaxial epidermis and cuticle thickness; e,f. abaxial epidermis and cuticle thickness. Scale bar $=20 \mu \mathrm{m}$.

na face abaxial e parênquima paliçádico foram registrados para os indivíduos ocorrentes na população da restinga herbácea, sendo apenas o parênquima lacunoso mais espesso na formação florestal (Tab. 2, Fig. 2). As maiores variações foram observadas para a epiderme na face adaxial e para o parênquima paliçádico (Tab. 2).

$\mathrm{O}$ índice de plasticidade fenotípica (IPF) mostrou que a espécie Tibouchina clavata é mais plástica para os atributos diâmetro basal do caule, seguido da massa fresca e massa seca foliares. Para os atributos anatômicos, o índice demonstra a baixa plasticidade para todos os atributos considerados (Tab. 3).

\section{Discussão}

Variáveis ambientais

A acidez do solo é uma propriedade que afeta a capacidade das plantas de assimilarem os nutrientes e a água disponível (Silva 1990). Solos mais ácidos, como observados nas formações de restinga estudadas, são esperados em ambientes tropicais em função da sua idade de formação (Casagrande 2003). Nesta condição, as plantas tendem a desenvolver raízes mais superficiais, localizadas logo abaixo da serapilheira, para facilitar a alocação de recursos nutricionais disponíveis no solo (Bonilha et al. 2013). 
A disponibilidade de potássio (K), assim como a capacidade de suprimento deste nutriente pelo solo, depende da capacidade de troca catiônica (CTC) do solo, além da ciclagem desse nutriente pelas plantas (Werle et al. 2008). O potássio $(K)$ tem grande influência sobre a produção de biomassa vegetal, contribuindo em até $10 \%$ da massa seca das plantas (Epstein \& Bloom 2006), fator este observado nos indivíduos da formação florestal que, em comparação aos de restinga herbácea, apresentam massa seca foliar 3,5 vezes maior.

A salinidade, representada pelo teor de sódio $(\mathrm{Na})$, é um fator de grande importância no desenvolvimento vegetal, uma vez que afeta negativamente o crescimento da planta em altura (Cavalcanti et al. 2005; Correia et al. 2005). Apesar da salinidade ser maior na formação florestal, os resultados obtidos para a altura média dos indivíduos nesta formação, três vezes superior àquela encontrada na formação herbácea com menor salinidade, sugerem que o efeito negativo da salinidade é possivelmente atenuado pelo maior teor de cálcio $(\mathrm{Ca})$ disponível no solo florestal. $\mathrm{O}$ cálcio $(\mathrm{Ca})$ em ambientes de estresse salino confere às plantas um grau de proteção maior frente aos danos provocados pelo sódio, uma vez que, por interação iônica, preserva as membranas plasmáticas das células, assim como impede a ruptura no potencial osmótico da planta (Epstein \& Bloom 2006).

A capacidade de troca catiônica dos solos representa a gradação da capacidade de liberação de vários nutrientes, favorecendo a manutenção da fertilidade do solo por um prolongado período e reduzindo ou evitando a ocorrência de efeitos tóxicos pelo excesso de alumínio $(\mathrm{H}+\mathrm{Al})$ que, por sua vez, pode dificultar a absorção de água e nutrientes pelas plantas (Casagrande 2003). Maiores concentrações de alumínio nos solos tropicais podem resultar do intemperismo gradativo e prolongado de outros minerais (Embrapa 2010). Mesmo a saturação por bases (V) sendo equivalente nas duas formações, o que implica numa condição distrófica de ambos os solos, o maior teor de CTC, $36 \%$ maior no solo florestal, o torna mais fértil.

\section{Atributos morfoanatômicos}

Todos os atributos morfológicos e anatômicos estudados mostraram variações significativas entre as populações das formações de restinga estudadas. Com exceção do conteúdo de matéria seca, da espessura da epiderme nas faces adaxial e abaxial da folha e da espessura do parênquima paliçádico, todos os atributos analisados tiveram maiores médias na formação florestal. Em contrapartida, torna-se mais pronunciado o caráter xeromórfico da população que habita a restinga herbácea, consideravelmente mais exposta às condições restritivas de água e nutrientes ao seu desenvolvimento. Caracteres xeromórficos são representados pela redução da área foliar, aumento da densidade estomática, cutícula espessa, esclerênquima e parênquima paliçádico mais desenvolvido, com sentido de reduzir a perda de água pela planta (Arens 1963; Fahn \& Cutler 1992).

O êxito de espécies em ocupar as regiões litorâneas depende das características estruturais dos seus órgãos vegetativos, as quais permitem a manutenção dos processos fisiológicos vitais, tais como a redução da área foliar, aumento da espessura foliar, presença de tecido aqüífero e mesofilo dorsiventral (Boeger \& Gluzezak 2006). A luminosidade, a disponibilidade hídrica e as condições edáficas influenciam inevitavelmente o desenvolvimento da planta. Logo, a falta ou o excesso de algum desses recursos pode influenciar no seu desenvolvimento (Schluter et al. 2003). Em meio a variações ambientais, a folha é considerada o órgão vegetal que mais prontamente responde a tais mudanças (Evert 2006).

Espécies que se desenvolvem sob alta intensidade luminosa tendem a apresentar folhas com áreas menores, o que proporciona um aumento na convecção de calor dissipado (Alves 2006), de modo a evitar o superaquecimento do mesofilo foliar e impedir a desidratação pelas altas taxas de transpiração (Klich 2000). As diferenças entre as áreas foliares obtidas corroboram os resultados encontrados para Nectandra oppositifolia Nees. (Lauraceae) em Floresta Ombrófila Densa Alto Montana e Floresta de Restinga, em que a área foliar diminuiu com o maior nível de luz incidente sobre as plantas (Todorovski et al. 2015). Estudo desenvolvido com espécies de dunas também mostra a redução da área foliar como uma tendência para minimizar a perda de água por evapotranspiração (Boeger \& Gluzezak 2006). Desta forma, a redução da área foliar nitidamente observada em Tibouchina clavata da formação herbácea pode ser uma estratégia de conservação de água em plantas que se desenvolvem em solos com menor capacidade de reter água e com baixa fertilidade, ao passo que a nutrição mineral é essencial para a produção da estrutura foliar 
(Brünig 1973). Ainda, representa uma estratégia biomecânica em indivíduos mais expostos ao vento (Niklas 1996), como ocorre na região pró-praia.

A área específica foliar (AEF) apresentou maior valor médio na Floresta da Restinga, indicando que os indivíduos de Tibouchina clavata investem mais em produção fotossintética, uma vez que nessa formação há maior disponibilidade de recursos (Vendramini et al. 2002). Por outro lado, o baixo valor de AEF observado prevaleceu nos indivíduos da formação com maior limitação de recursos nutricionais e água disponível. Tal característica xeromórfica geralmente está relacionada ao maior desenvolvimento de tecidos esclerenquimáticos (Turner 1994), como encontrado em outras plantas lenhosas crescendo sobre solos arenosos da área estudada (Melo Jr. \& Boeger 2016) e em plantas herbáceas não suculentas de dunas arenosas (Li et al. 2005; Boeger \& Gluzezak 2006). Dessa forma, considera-se a AEF um indicador de estratégias ecológicas relacionadas à produtividade em ambientes sob estresse (Niklas \& Christianson 2011) e à fertilidade do solo (Hodgson et al. 2011). Em conjunto, tais características auxiliam na longevidade das folhas, aumentando o carbono por unidade de investimento (Edwards et al. 2000). Em acréscimo, a esclerofilia pode ser uma resposta xeromórfica aos solos oligotróficos pois afetam o metabolismo do nitrogênio (Loveless 1962). Estudo realizado em floresta sobre solos arenosos mostrou que a indisponibilidade de nutrientes provocou maior grau de xeromorfismo em folhas mais espessas, menores em área e com parênquima paliçádico mais espesso (Boeger \& Wisniewski 2003), o que corrobora a situação aqui encontrada para a população de $T$. clavata na formação herbácea da restinga.

Os menores valores de altura e diâmetro basal do caule dos indivíduos da formação herbácea podem ser entendidos como uma resposta arquitetural de Tibouchina clavata face à maior incidência de ventos e à escassez de nutrientes e água na região pós-praia. A menor oferta de água no solo e a deficiência nutricional podem resultar num menor crescimento da parte aérea das plantas (Beutler \& Centurion 2004). Além disso, a quantidade de luz que penetra nos tecidos pode alterar as taxas de crescimento da planta, à medida que acentua ou reduz a produção fotossintética, (Volgemann 1994) e influenciar no desenvolvimento da sua altura máxima (Falster \& Westoby 2005).
A variação na espessura da epiderme, incluindo a cutícula, também foi reconhecida como caráter distintivo entre os indivíduos de Tibouchina clavata das duas formações de restinga, sendo tal tecido mais espesso na formação herbácea quando comparada ao da florestal. Epiderme espessada na face foliar adaxial é considerada uma característica tipicamente xeromórfica (Fahn \& Cutler 1992) e representa uma estratégia funcional que reduz o déficit de água provocado pelo processo de transpiração em folhas mais expostas diretamente à irradiância solar e às temperaturas altas (Evert 2006), como é observado na formação de restinga herbácea, além de aumentar a reflexão da luz incidente (Chadzon \& Kaufmann 1993).

A relação inversamente proporcional observada para a espessura dos parênquimas fotossintetizantes pode ser explicada pela incidência luminosa. Os indivíduos de Tibouchina clavata da formação herbácea, mais expostos à radiação luminosa, possuem parênquima paliçádico mais espesso quando comparados aos indivíduos da formação florestal, mais sombreados. O parênquima paliçádico altera-se de acordo com o gradiente lumínico e apresenta-se espessado à medida que a luminosidade aumenta (Taiz \& Zeiger 2013). Voltan et al. (1992) em trabalho com cultivares de Coffea arabica L. (Rubiaceae) expostos a diferentes intensidades luminosas, indicam que em condições de radiação elevada ocorre espessamento foliar induzido pela expansão volumétrica das células do mesofilo e pelo alongamento celular do parênquima paliçádico, o qual melhor otimiza a captura da luz direta e corresponde ao observado em T. clavata. A maior espessura do parênquima paliçádico, em plantas de ambientes com maior luminosidade facilita a penetração da radiação solar incidente na folha (Volgemann et al. 1996) e acentua seu potencial fotossintético (Evert 2006).

Por outro lado, o parênquima lacunoso mostrou-se mais espesso nos indivíduos florestais quando comparados aos da formação herbácea em Tibouchina clavata. Parênquima lacunoso mais desenvolvido permite um melhor aproveitamento da luz em áreas mais sombreadas (Borges 2009). Em ambientes com menor intensidade luminosa as folhas são menos espessas em decorrência das poucas camadas de parênquima paliçádico e maior desenvolvimento do parênquima lacunoso, cujo formato irregular promove a reflexão e refração do raio luminoso no mesofilo e aumenta sua absorção (Cao 2000). Estudo realizado com espécies co- 
ocorrentes de restinga em gradiente lumínico demonstrou que em ambientes com maior nível de sombreamento o parênquima esponjoso é até 2,5 vezes mais espesso que o paliçádico, aumentando a capacidade da planta em capturar a luz difusa (Melo Jr. \& Boeger 2016).

Os maiores valores do índice de plasticidade para os atributos morfológicos sinalizam a existência de um filtro ambiental atuante sobre a espécie em estudo, o que não é observado para os atributos anatômicos, caracterizando, assim, maior herdabilidade das características anatômicas e a sua canalização face aos gradientes de solo e luz. As plantas podem responder a flutuações espaciais ou temporais no ambiente, diretamente mediante alteração da sua morfologia e fisiologia (Pugnaire \& Valladares 2007). Tibouchina clavata demonstrou ser morfologicamente plástica e permite compreender os efeitos dos fatores limitantes da restinga sobre o desenvolvimento vegetal, com destaque às condições nutricional, hídrica e lumínica que induzem ao xeromorfismo. Desta forma, é um bom modelo para se avaliar os efeitos das variáveis ambientais sobre as respostas vegetais.

\section{Agradecimentos}

Ao Programa de Pesquisa em Biodiversidade da Mata Atlântica (PPBio-MA) e ao Programa Institucional de Pesquisas em Ciências Ambientais da Univille, o suporte à pesquisa.

\section{Referências}

Almeda, F.; Goldenberg, R.; Michelangeli, F.A.; Cifuentes, H.M.; Renner, S.S.; Stone, D.; Ulloa, C.U. \& Triebel, D. 2015. Melastomataceae.Net. A site with information on the biodiversity of Melastomataceae. Disponível em $<$ http://www. melastomataceae.net>. Acesso em 12 outubro 2015.

Alves, A.C.A. 2006. Efeito das diferentes intensidades luminosas na morfoanatomia foliar de duas espécies de plantas medicinais em consórcio com Ilex paraguariensis A. St.-Hil. (Aquifoliaceae). Dissertação de Mestrado em Botânica. Universidade Federal do Paraná, Curitiba. 61p.

Arens, K. 1958. Considerações sobre as causas do xeromorfismo foliar. Boletim da Faculdade de Filosofia, Ciências e Letras, Universidade de São Paulo. Botânica 15: 25-56.

Bachtold, B. \& Melo Júnior, J.C.F. 2015. Plasticidade morfológica de Calophyllum brasiliense Camb. (Calophyllaceae) em duas formações de restinga no sul do Brasil. Acta Biológica Catarinense 2: 21-32.
Baraloto, C.; Paine, C.E.T.; Patiño, S.; Bonal, D.; Hérault, B. \& Chave, J. 2010. Funcional trait variation and sampling strategies in species-rich plant communities. Functional Ecology 24: 208-216.

Beutler, A.N. \& Centurion, J.F. 2004. Compactação do solo no desenvolvimento radicular e na produtividade de soja. Pesquisa Agropecuária Brasileira, Brasília 39: 581-588.

BFG. 2015. Growing knowledge: an overview of seed plant diversity in Brazil. Rodriguésia 66: 1085-1113.

Borcard, D.; Gillet, F. \& Legendre, P. 2011. Numerical ecology with R. Springer, New York. 319p.

Boeger, M.R.T. \& Gluzezak, R.M. 2006. Adaptações estruturais de sete espécies de plantas para as condições ambientais da área de dunas de Santa Catarina, Brasil. Iheringia, Série Botânica 61: 73-82.

Boeger, M.R.T. \& Wisniewski, C. 2003. Comparação da morfologia foliar de espécies arbóreas de três estádios sucessionais distintos de floresta ombrófila densa (Floresta Atlântica) no Sul do Brasil. Revista Brasileira de Botânica 26: 61-72.

Bonilha, R.M.; Casagrande, J.C.; Soares, M.R. \& Reis-Duarte, M. 2013. Characterization of the soil fertility and root system of restinga forests. Revista Brasileira de Ciência do Solo 36: 1804-1813.

Borges, M.G.E. 2009. Influência do ambiente construído no microclima urbano - estudo de caso no Campus da Universidade Federal de Santa Catarina-Florianópolis. Dissertação de Mestrado em Arquitetura e Urbanismo. Universidade Federal de Santa Catarina, Florianópolis. 154p.

Brünig, E.F. 1973. Species rickness and stand diversity in relation to site and succession forests in Sarawak and Brunei (Borneo). Amazoniana 4: 293-320.

Cao, K.F. 2000. Leaf anatomy and chlorophyll content of 12 woody species in contrasting conditions in a Bornean heath Forest. Canadian Journal of Botany 78: 1245-1253.

Casagrande, J.C. 2003. Considerações sobre recuperação da fertilidade do solo para áreas degradadas. In: Anais do seminário temático sobre recuperação de áreas degradadas, São Paulo. Pp. 92-93.

Cavalcanti, M.L.F.; Fernandes, P.D.; Gheyi, H.R.; Barros Júnior, G.; Soares, F.A.L. \& Siqueira, E.C. 2005. Tolerância da mamoneira BRS 149 à salinidade: Germinação e características de crescimento. Revista Brasileira de Engenharia Agrícola e Ambiental 9: 57-61.

Chagas, M.G.S.; Silva, M.D.; Galvíncio, J.D. \& Pimentel, R.M.M. 2008. Variações foliares em grupos funcionais vegetais de uma paisagem de Restinga, Pernambuco-Brasil. Revista Brasileira de Geografia Física 1: 50-63.

Chadzdon, R.L. \& Kaufmann, S. 1993. Plasticity of leaf anatomy of two rain forest Shrubs in relation 
to photosynthetic light acclimation. Functional Ecology 7: 385-394.

Climate-Data. 2015. Temperatura. Disponível em $<$ http://pt.climate-data.org/location/28141/>. Acesso em 2 maio 2015.

Cordazzo, C.V.; Paiva, J.B. \& Seeliger, U. 2006. Guia ilustrado plantas da costa sudoeste atlântica. USEB, Pelotas. 107p.

Correia, K.G.; Fernandes, P.D.; Gheyi, H.R.; Gurgel, M.T. \& Rodrigues, L.N. 2005. Crescimento do amendoinzeiro irrigado com águas salinas. Revista Brasileira de Engenharia Agrícola e Ambiental 9: 81-85, suplemento.

EMBRAPA. 2013. Sistema brasileiro de classificação de solos. $3^{\text {a }}$ ed. EMBRAPA, Brasília. 353p.

Epstein, E. \& Bloom, A.J. 2006. Nutrição mineral de plantas: princípios e perspectivas. Editora Planta, Londrina. 403p.

Evert, R.F. 2006. Esau's plant anatomy: meristems, cells and tissues of plant body: their structure, function and development. John Wiley \& Sons, New Jersey. 176p.

Falster, D.S. \& Westoby, M. 2005. Alternative height strategies among 45 dicot rain forest species from tropical Queensland, Australia. Journal of Ecology 93: 521-535.

Fahn, A. \& Cutler, D.F. 1992. Xerophytes. Gebrüder Borntraeger, Berlin. 176p.

Goldenberg, R. 2004. O gênero Miconia (Melastomataceae) no estado do Paraná, Brasil. Acta Botanica Brasilica 18: 927-947.

Goldenberg, R.; Baumgratz, J.F.A. \& Souza, M.L.D.R. 2012. Taxonomia de Melastomataceae no Brasil: retrospectiva, perspectivas e chave de identificação para os gêneros. Rodriguésia 63: 145-161.

Guimarães, P.J.F. \& Martins, A.B. 1997. Tibouchina sect. Pleroma (D. Don) Cogn. (Melastomataceae) no estado de São Paulo. Revista Brasileira de Botânica 20: 11-33.

Hodgson, J.G.; Montserrat-Martí, G.; Charles, M.; Jones, G. \& Wilson, P. 2011. Is leaf dry matter content a better predictor of soil fertility than specific leaf area? Annals of Botany 108: 13371345 .

Johansen, D.A. 1940. Plant microtechnique. McGrawHill, New York. 523p.

Klich, M.R. 2000. Leaf variations in Elaeagnus angustifolia related to environmental heterogeneity. Environmental and Experimental Botany 44: 171-183.

Köppen, W. 1948. Climatologia: con un estudio de los climas de la tierra. Fondo de Cultura Economica, Mexico. 478p.

Li, Y.; Johnson, D.A.; Su, Y.; Cui, J. \& Zhang, T. 2005. Specific leaf area and leaf dry matter content of plants growing in sand dunes. Botanical Bulletin of Academia Sinica 46: 127-134.
Loveless, A.R. 1962. Further evidences to support a nutritional interpretation of sclerophylls. Annals of Botany 26: 549-561.

Melo Júnior, J.C.F. \& Boeger, M.R.T. 2016. Leaf traits and plastic potential of plant species in a lightedaphic gradient from restinga in southern Brazil. Acta Biologica Colombiana 21: 51-62.

Melo Júnior, J.C.F. \& Boeger, M.R.T. 2015. Riqueza, estrutura e interações edáficas em um gradiente de restinga do Parque Estadual do Acaraí, Estado de Santa Catarina, Brasil. Hoehnea 42: 207-232.

Niklas, K.J. 1996. Differences between Acer saccharum leavesfrom open and wind-protected sites. New Phytologist 143: 19-31.

Niklas, K.J. \& Christianson, M.L. 2011. Differences in the scaling of area and mass of Ginkgo biloba (Ginkgoaceae) leaves and their relevance to the study of specific leaf area. Botany 98: 1381-1386.

Paiva, J.G.A.; Fank-de-Carvalho, S.M.; Magalhães, M.P. \& Graciano-Ribeiro D. 2006. Verniz vitral incolor 500: uma alternativa de meio de montagem economicamente viável. Acta Botanica Brasilica 20: 257-264.

Pugnaire, F.I. \& Valladares, F. 2006. Functional Plant Ecology. CRC Press, New York, London. 744p.

Schluter, U.; Muschak, M.; Berger, D. \& Altmann, T. 2003. Photosynthetic performance of an Arabidopsis mutant with elevated stomatal density (sdd1-1) under different light regimes. Journal of Experimental Botany 54: 867-874.

Silva, S.M. 1990. Composição florística e fitossociologia de um trecho de floresta de restinga na Ilha do Mel, município de Paranaguá. Dissertação de Mestrado. Universidade Estadual de Campinas, Campinas. 146p.

Silva, C.R.A.; Leite, K.R.B.; Ferreira, L.M.S.L.; Silva, M.S. \& Silva, L.B. 2014. Influência da altitude na plasticidade foliar de Clusia obdeltifolia Bittrich (Clusiaceae). Revista Nordestina de Biologia 23: 29-48.

Silva, K.R.; Melo Jr., J.C.F. \& Boeger, M.R.T. Variações fenotípicas em Andira fraxinifolia Benth. (Fabaceae) em duas fitofisionomias de restinga. Hoehnea 43: 229-237.

Taiz, L. \& Zeiger, E. 2013. Fisiologia vegetal. 5a ed. Artmed, Porto Alegre. 954p.

Todorovski, E.C.D.; Melo Júnior, J.C.F.; Amorim, M.W. \& Silva, M.M. 2015. Potencial plástico de Nectandra oppositifolia Nees. (Lauraceae) em fisionomias de floresta ombrófila densa e restinga. Natureza on line 13: 70-76.

Turner, J.M. 1994. Sclerophylly: primarily protective? Functional Ecology 8: 669-675.

Valladares, F.; Sanches-Goems, D. \& Zavala, M.A. 2006. Quantitative estimation of phenotypic plasticity: bridging the gap between the evolutionary concept and its ecological applications. Journal of Ecology 94: 1103-1116. 
Vogelmann, T.C.; Bornman, J.F. \& Yates, D.J. 1996. Focusing of light by leaf epidermal cells. Physiologia Plantarum 98: 43-56.

Voltan, R.B.Q.; Fahl, J.I. \& Carelli, M.L.C. 1992. Variação na anatomia foliar de cafeeiros submetidos a diferentes intensidades luminosas. Revista Brasileira de Fisiologia Vegetal 4: 99-105.

Werle, R.; Garcia, R.A. \& Rosolem, C.A. 2008. Lixiviação de potássio em função da textura e da disponibilidade do nutriente no solo. Revista Brasileira de Ciência do Solo 32: 2297-2305.

Witkowski, E.T.F. \& Lamont, B.B. 1991. Leaf specific mass confounds leaf density and thickness. Oecologica 88: 486-493.

Wurdack, J.J. 1962. Melastomataceae of Santa Catarina. Sellowia 14: 109-217.

Zar, J.H. 1999. Biostatistical analysis. $4^{\mathrm{a}}$ ed. PrenticeHall, Inc., New Jersey. 663p. 